\title{
Meredith Monk: a arte nas fronteiras das linguagens
}

\author{
Meredith Monk: art in the \\ boundaries between languages
}

Wânia Mara Agostini Storolli ${ }^{1}$ 


\section{Resumo}

Este artigo tem como tema a produção artística de Meredith Monk, que transcende as categorias tradicionais, concentrando-se especialmente em Juice - a theater-cantata in three installments de 1969. A partir de considerações sobre a estrutura e apresentação desta obra, o estudo observa os diversos aspectos que situam esta produção no contexto do surgimento de novas formas de manifestação artística nas últimas décadas do século $X X$, tais como a relativização das categorias, a atuação em espaços não convencionais, o uso da arquitetura como estrutura, a mixagem de linguagens e a proposta de novas formas de percepção.

Palavras-chave: Meredith Monk; performance; arte multimídia; instalação

\section{Abstract}

This article is about Meredith Monk's artistic production, which transcends traditional categories, specially focusing on Juice - a theater-cantata in three installments of 1969. Based on considerations on the structure and presentation of this work, the study looks at the various aspects that place this production in the context of the emergence of new forms of artistic expression in the last decades of the twentieth century, such as the relativization of traditional categories, performance in unconventional spaces, the use of architecture as structure, the mixing of languages and the proposal of new forms of perception.

Keywords: Meredith Monk; performance; multimedia art; installation 
Cidade de New York, ano de 1969. As rampas do Solomon R. Guggenheim Museum povoam-se de corpos e vozes, um coro de aproximadamente cem pessoas, vestidas de branco, sobem e descem suas rampas. Seus sons murmurantes envolvem, comprimem e expandem o espaço em torno de quatro performers pintados e vestidos de vermelho, concebidos como uma só figura. Um violino ao fundo preenche o espaço com a sonoridade de uma frase que se repete. Em frente ao Museu, na famosa Quinta Avenida de New York, um performer vai e vem sobre um cavalo! Estas cenas e ações integram a primeira parte da peça Juice - a theater-cantata in three installments de Meredith Monk.

A segunda parte de Juice é encenada quase um mês depois no Minor Latham Playhouse do Barnard College. Nesta parte, a figura composta pelas quatro performers em vermelho, uma das quais a própria Meredith Monk, se desmembra em quatro pessoas diferentes. São indivíduos que se identificam dizendo seus nomes e endereços. O cavalo, que na primeira parte ia e vinha pela Quinta Avenida, é agora um cavalo de brinquedo, sobre o qual há uma garotinha. A estratégia, utilizada por Meredith Monk, começa a revelar um movimento de aproximação, que ficará ainda mais perceptível na terceira e última parte de Juice. Esta ocorre no loft da autora, no centro da cidade de New York, porém aí não há mais a presença de performers ao vivo. As quatro figuras em vermelho aparecem em close-up em um monitor. Em vídeo falam, cantam e fritam ovos. Dispostos pelo espaço, diversos objetos utilizados na primeira parte, encenada no Guggenheim Museum, podem ser observados pelo público. As botas dos performers e outros resíduos e reminiscências da performance daquele dia podem ser tocados. O cavalo está presente como uma pequenina figura, reafirmando o movimento de aproximação progressiva.

Juice: a theatre cantata in 3 installments é uma das produções de Meredith Monk que expressa claramente a profunda transformação pela qual passam os conceitos artísticos nas décadas de 60 e 70 e que conduz à geração e afirmação de novos gêneros e formas de manifestação, influenciando e reorientando a produção artística contemporânea.

\section{Meredith Monk e o contexto das transformações}

Meredith Monk pode ser considerada como uma das principais criadoras performáticas entre as que surgiram nas últimas décadas do século $X X$, atuando como compositora, dramaturga, coreógrafa, cineasta, dançarina e cantora. A maior parte de suas criações abrange o território da intersecção entre as artes, porém com forte ênfase na composição musical e na utilização da voz como instrumento principal. Embora seja difícil enquadrar Meredith Monk em categorias, ela própria se considera primordialmente uma compositora. Em suas obras a criação musical opera como uma cola, que serve para aglutinar e estruturar os vários componentes de suas performances. Em conversa com William Duckworth, Meredith Monk afirma que, mesmo quando trabalha com imagens e teatro, pensa em termos musicais e organiza o material como em uma composição musical (Duckworth, 1999).

Meredith Monk desenvolve sua criação exatamente no sutil território das fronteiras entre as diversas linguagens artísticas, expandindo em praticamente todas suas 
criações o conceito de arte multimídia. Na verdade, sua obra desafia as categorias tradicionais, como observa John Perreault (Jowitt, 1997). Desenvolvendo seus projetos desde os anos 1960, Meredith Monk tem explorado o novo território da arte multimídia, integrando as diversas linguagens artísticas e diferentes mídias. Sua trajetória artística singular confunde-se com os próprios caminhos da arte contemporânea após os anos sessenta, período de forte ebulição cultural e transformação de conceitos. Sua produção artística revela alguns caminhos trilhados pelos representantes da Performance Art, gênero que se estrutura também com sua cooperação. Porém, sua obra não se enquadra totalmente sob este gênero e situa-se frequentemente num território "entre", que não permite uma categorização exata.

O contexto sócio cultural no qual Meredith Monk vive e desenvolve-se profissionalmente é determinante para sua trajetória artística. Em 1964, após seus estudos no Sarah Lawrence College, Meredith Monk estabelece-se na cidade de New York, onde começa a fazer peças solos em galerias e em locais como a Judson Church, espaço onde são apresentadas muitas obras da vanguarda neste período. Segundo Meredith Monk, este era um tempo ideal para vir para New York, um período artisticamente estimulante, em que havia um diálogo intenso entre artistas de diferentes linguagens (Monk, 2012). Nos anos 1960 a cidade de New York foi palco de fortes e importantes transformações culturais. O movimento artístico reinante nesta cidade tinha muito em comum com o movimento dadaísta do início do século $X X$, iniciado em Zurique, lembra Jowitt (1997). New York era tomada por eventos do grupo Fluxus e Festivais de Avant-garde, em que eram exibidas criações artísticas, que além de fazer uso dos novos recursos midiáticos e tecnológicos que surgiam, apontavam para uma dissolução crescente da compartimentalização das diversas linguagens. Também neste período em New York, o compositor John Cage atuava na New School for Social Research, influenciando em seus cursos uma geração de músicos e artistas e defendendo o fim das barreiras entre arte e vida cotidiana. Happenings e eventos multimídia multiplicavam-se, apontando para a surgimento de novos gêneros artísticos.

\section{Novos espaços de performance: a arquitetura como estrutura}

A produção artística de Meredith Monk é marcada pela escolha de espaços não convencionais para suas apresentações. Em conversa com Liza Bear, Meredith Monk afirma: "Sempre trabalhei em espaços arquitetônicos concretos e fiquei fora do palco" (Jowitt, 1997, p. 89) 2 . Uma das primeiras produções de Meredith Monk que demonstra seu desejo de explorar locações específicas e ao mesmo tempo experimenta a ideia de poder dividir uma peça em partes, é Blueprint de 1967. Dividida em 2 partes, a primeira é apresentada na Judson Gallery em New York, consistindo em uma espécie de instalação, um teatro visual, com imagens simples, segundo a própria artista. A segunda parte é apresentada apenas um mês depois no porão e no santuário da Judson, de forma a explorar todo o espaço do prédio através de repetições e variações das imagens apresentadas na primeira parte (Monk, 2014).

2 I've always worked within concrete architectural spaces and stayed off the stage. (Tradução nossa) 
A procura de Meredith Monk por locais de performance que não o palco tradicional, expressa sua intenção de fazer uso do espaço como este existe no mundo real, revelando a mágica que carrega. Em conversa com Bonnie Marranca, a artista questiona: "Como fazer de maneira a ver este [espaço] de diferentes formas?" (Monk, 2014, p. 27) ${ }^{3}$. Assim, diversas obras suas propõem a ressignificação do espaço circundante, em especial da própria cidade em que vive - New York. Esta se transforma não apenas em cenário, mas integra o que tradicionalmente seriam os locais designados para palco e plateia, colocando em cheque esta divisão e procedendo simultaneamente a uma mixagem entre elementos provenientes da ficção e da realidade do cotidiano.

Juice: a theatre cantata in 3 installments é criada na sequência de algumas peças encenadas por Meredith Monk e denominadas Tour Pieces. Nestas peças, a estrutura das performances tem estreita relação com os espaços onde são encenadas, o que leva a artista a comentar que de fato nestes trabalhos a arquitetura teria sido utilizada como estrutura (Monk, 2014). Uma das primeiras peças desta série foi Tour: Dedicated to Dinosaurs (1968), realizada no Natural History Museum in Washington da Smithsonian Institution. Neste edifício, Meredith Monk trabalha com setenta pessoas que se movem pelos espaços do museu, cantando e realizando gestos simples. Um mês depois outra Tour Piece é encenada no Contemporary Museum of Chicago. Baseada na estrutura do edifício, segundo Meredith Monk (2014), é denominada Tour: Barbershop. Nesta peça, a artista já trabalha com a noção de aproximação, estratégia que será explorada logo em seguida na criação de Juice. Segundo Meredith Monk, esta seria uma forma de se pensar sobre a distância entre os performers e a audiência (Monk, 2014).

Em Juice, tal como na obra posterior, Needlebrain Loyd and the Systems Kid: a live-movie (1970), além do uso de diferentes espaços de encenação, há também a inclusão de um grande número de performers. Juice envolve aproximadamente uma centena de performers e se divide em três partes, que são apresentadas não somente em locações diversas como também em dias diferentes, abrangendo um período de dois meses no total. Juice convida a audiência a realizar uma jornada. No entanto, a audiência não é conduzida de um local a outro como em algumas obras posteriores de Meredith Monk, mas deve ir por conta própria aos espaços determinados, em datas previamente marcadas.

Os cenários de Juice são espaços em constante transformação, multidimensionais e resultantes da presença dos diversos componentes e da forma como se organizam e interagem com o todo. Assim, ao contemplar a cena do cavalo em frente ao museu, o público tem a Quinta Avenida e o Central Park de New York ao fundo como parte de sua visão panorâmica, integrando este cenário, assim como eventuais pedestres e carros em movimento. Esta parte específica da cidade de New York faz parte do cenário da primeira parte de Juice, que se completa com o espaço interno do Guggenheim Museum, suas rampas e halls, onde se desenrolam as outras ações. Meredith Monk integra assim os espaços arquitetônicos do edifício e a paisagem urbana ao seu redor como parte de sua obra. Tal qual em um filme ao vivo, es- 
tes cenários delineiam um espaço, que é redesenhado constantemente quando nele performers e audiência desfilam suas ações. O mesmo ocorre com o espaço da performance enquanto espaço sonoro, que incorpora o ruído da cidade na parte externa ao museu e que, na parte interna, resulta do amálgama produzido entre murmúrios e melodias entoadas pelas vozes e pelo violino e sons da audiência e dos performers em movimento.

\section{Visualidade e imersão}

Juice propõe diferentes formas de percepção da informação visual e sonora. Apenas considerando a primeira parte de Juice, apresentada no Guggenheim, pode-se observar que a obra apresenta três perspectivas distintas para a percepção do espaço, visual e sonoro. O museu oferece uma ideia de espaço escultural e tridimensional, como observa Meredith Monk (2014). No começo da performance o público está no térreo, olhando para cima para as rampas espiraladas do museu, onde os performers estão dispostos em diferentes locais e executam suas linhas melódicas. Segundo Meredith Monk, neste momento há o predomínio de uma experiência sonora imersiva (Monk, 2014). Logo após, na segunda seção, o público pode subir e descer as rampas e direcionar sua atenção para os diversos eventos, entre vinte e vinte e cinco, que ocorrem nos pequenos espaços, tais como quadros em uma exposição. Nesta seção o público pode observar de perto a ação escolhida. Já na última seção, há uma inversão de posições - enquanto a audiência permanece nas rampas, os performers descem para o hall no térreo e realizam uma dança e um canto, fazendo uso da harpa de boca. De certa forma nesta peça, comenta Meredith Monk, "o edifício inteiro foi virado de dentro para fora. Você [a audiência] estava olhando a partir destes diferentes ângulos de aspectos da arquitetura do edifício" (Monk, 2014, p. 31) 4 .

A segunda parte de Juice, encenada no Minor Latham Theatre, é realizada como em um quadro, com uma perspectiva "plana", segundo Meredith Monk, para mostrar que consideramos como "natural" a disposição espacial estabelecida pelo arco do proscênio (Monk, 2014). A questão visual e as diferentes perspectivas transformamse em tema para Meredith Monk, também como consequência de questões físicas relacionadas a sua visão. A artista nasceu com estrabismo, condição em que os olhos funcionam separadamente e se focados simultaneamente no mesmo objeto levam a uma visão dupla. Assim, o cérebro aprende a alternar as informações provenientes de cada olho para evitar a imagem dupla. Segundo a própria artista, sua visão é mais plana, percebendo mais a distância do que a profundidade. Assim, nesta segunda parte de Juice, Meredith Monk trabalha com a noção de camadas horizontais, onde as ações são dispostas como em uma pintura. Dos cem performers atuantes na primeira parte de Juice, no Guggenheim, restam nove personagens principais na segunda parte, no Minor Latham Theatre, quando estes podem ser vistos mais de perto. A ideia de aproximação, de um quadro geral e uma visão panorâmica, predominantes no Guggenheim, para um plano médio no Minor Latham Theatre, remete aos conceitos

${ }^{4}[\ldots]$ the whole building was turned inside out. You were looking from these different angles of aspects of the architecture of the building. (Tradução nossa) 
provenientes da linguagem cinematográfica. Finalmente, na última parte de Juice, apresentada no loft, há uma espécie de zoom, com a imagem dos quatro performers em vermelho em vídeo e objetos das outras duas partes dispostos pelo espaço.

Juice resulta de uma integração de linguagens, que com uma narrativa não linear estimula a interatividade e oferece ao público em diversos momentos uma experiência imersiva. Estes aspectos têm sido utilizados, segundo Klich e Scheer, para definir a performance multimídia (Klick, Scheer, 2012, p. 8-9). Embora o conceito de imersão apareça fortemente no contexto do uso de mídias digitais nas formas de arte contemporânea, ele tem uma extensa história relacionada à prática teatral. $\mathrm{Na}$ imersão dramática tradicional muitas vezes a audiência se projeta na trama dramática, de forma a perder contato com sua própria realidade. Porém, segundo observam Klich e Scheer:

A percepção de que a imersão no teatro implica 'perder-se' no drama, ou seja, uma compreensão de imersão como faculdade puramente cognitiva, é limitada, pois desconsidera o potencial de uma experiência sensorial e corporal como a que um espectador pode ter em um ritual ou na arte da performance contemporânea ou talvez mesmo no teatro pós-dramático (Klich, Scheer, 2012, p. 128)5.

A arte contemporânea nas suas múltiplas manifestações tem procurado criar condições para uma imersão tanto cognitiva como sensorial, de forma a envolver o público visceralmente. Neste tipo de proposta artística, é através da experiência corpórea que o público acessa texto, imagem e som, num processo que funde informação e materialidade (Klich, Scheer, 2012).

Em Juice, na primeira parte realizada no Guggenheim Museum, o público pode ter a experiência da imersão sensorial, sendo envolvido pelas vozes e sons dos performers, percebendo as diferentes possibilidades de perspectiva visual e sonora através de sua própria movimentação pelo espaço. A imersão estimula o contato do público com seus próprios sentidos, que é envolto pelas sonoridades, imagens e ações propostas e, mais do que isto, ele próprio em movimento constitui parte integrante destas. Meredith Monk, através das formas de encenação e escolha dos diversos locais da performance oferece ao público uma oportunidade de acessar novos modos de percepção. Assim, na última parte de Juice, o público pode tocar e cheirar os objetos que foram utilizados nas duas primeiras partes, num processo que completa e amplia a imersão sensorial. Não é proposto um mundo artificial, mas sim a imersão no espaço real da performance, no aqui e no agora. Essa tendência de criar uma experiência de imersão em tempo e espaços reais é observada durante todo o século XX na produção das vanguardas. Na produção teatral, a intenção tem sido a de quebrar a "quarta parede" e deixar a audiência imersa no mesmo espaço da performance (Klich, Scheer, 2012). Em sua proposta de imersão, Juice aproxima a arte da vida cotidiana, indo ao encontro dos novos conceitos artísticos. "Com o final da distância entre audiência e evento, intensifica-se o grau de imersão" (Klich, Scheer, 2012, p. 132)6.

\footnotetext{
${ }^{5}$ The perception that immersion in theatre involves 'losing' oneself in the drama, that is, an understanding of immersion as a purely cognitive faculty, is limited as it disregards the potential for a sensory, corporeal experience such as that which a spectator might have in ritual or contemporary performance art or perhaps even in post-dramatic theatre. (Tradução nossa)

${ }^{6}$ With the dying of distance between the audience and the event, the greater is the degree of immersion. (Tradução nossa)
} 


\section{Entre realidade e ficção: a relativização das categorias}

A performance de Juice é gerada ao se construir um espaço de mixagem de linguagens pela ação dos corpos, suas sonoridades e movimentações. A proposta de Juice é inovadora por mixar performers e audiência em um mesmo espaço, de forma que essas categorias deixam de ser claramente definidas. Não é somente a partir da atuação dos performers, mas também pela atuação da audiência, que a performance se materializa.

$\mathrm{Na}$ segunda parte de Juice, que tem lugar em um espaço de performance mais convencional, ocorre uma transformação abrupta da realidade teatral para o cotidiano, como comenta Berger (1997), quando os quatro performers em vermelho começam a se apresentar. Meredith Monk diz seu nome e onde vive, formulando afirmações com base na sua vida pessoal. Neste momento não há uma personagem dramática no sentido usual do termo. Acredite-se ou não nos dados apresentados, estes são parte de uma criação que pode abranger tanto informações verídicas como fictícias, instaurando-se uma certa ambivalência. Segundo Berger, "o mistério nesta metamorfose é como se alguém usando uma máscara lentamente dela se despisse, somente para revelar exatamente a mesma face sob a máscara" (Berger, 1997, p. 45) ${ }^{7}$. A tênue divisa entre ficção e realidade torna-se mais nebulosa, levando à contestação deste tipo de categorização. Meredith Monk funde aqui o mundo real e o mundo que inventa. Ao se apresentar para a audiência como Meredith Monk, moradora de New York, mostra que tudo ali é parte dela, que o mundo criado e encenado no palco é uma extensão de sua pessoa. Esta questão expande-se na contemporaneidade através da mixagem entre real e virtual, conforme as tecnologias se fazem cada vez mais presentes na vida cotidiana e nas artes. A diferenciação entre o que é real e o que é virtual mostra-se como extremamente sutil e, muitas vezes, impossível de ser percebida - tornando-se tema constante do fazer artístico contemporâneo.

A última parte de Juice revela claramente um paradoxo, que é explicitado pelo uso da mídia vídeo e dos elementos específicos da linguagem cinematográfica, como as alterações de enquadramento através do uso do zoom progressivo. Embora as imagens das personagens principais estejam mais próximas, devido ao uso do close-up, possibilitado pelo uso do vídeo, suas presenças, que eram físicas durante as duas primeiras partes de Juice, transformam-se agora em presença virtual. Há claramente um jogo de relações, entre o real e o virtual, fronteiras que são aqui abaladas.

\section{Nos espaços "entre": transpondo linguagens}

Em Juice, como acima observado, há um movimento contínuo de aproximação, uma espécie de zoom progressivo, finalizando com um enquadramento similar ao close-up na última parte. A memória é então chamada a participar, pois a apreciação das peças em exibição no loft remetem a audiência às duas primeiras partes da peça, assim como a presença do cavalo e sua contínua miniaturização. Como Meredith

${ }^{7}$ The mystery in this metamorphosis is as if someone wearing a mask slowly peels it off, only to reveal the exact same face beneath the mask. (Tradução nossa) 
Monk observa, a peça marca sua forma de trabalhar o espaço e uma tentativa de subverter tanto o espaço quanto o tempo (2012). Já o título da obra, Juice - a Theatre Cantata in three installments, revela a mixagem de formas. Trata-se de uma apresentação musical com a forma cantata ou de uma performance teatral dividida em partes? De fato, Juice situa-se no sutil território das fronteiras, realizando-se enquanto apresentação musical, performance teatral e principalmente como uma espécie de instalação. Juice resulta do trânsito entre as linguagens, em especial da transposição de conceitos e estratégias de uma linguagem para outra.

Como Mark Berger observa, Meredith Monk consegue explorar e expandir o aspecto não verbal de um teatro de colagens dentro de um formato de narrativa (Berger, 1997). Existem figuras, mini-enredos, desenvolvimento, mas tudo está em fluxo, organizando-se e reorganizando-se em tempo presente num espaço multidimensional e sonoro, que se caracteriza como espaço da performance com o decorrer da performance.

Ao comentar sobre a integração das diversas linguagens nas novas formas e gêneros artísticos, Meredith Monk relaciona este fato a uma necessidade das formas de vida contemporâneas. As formas artísticas são indicativas do nosso mundo atual. A artista ressalta a importância de realizar uma forma de arte que possa estimular a multiplicidade de modos de percepção integrados e assim gerar uma percepção mais completa e abrangente. Em conversa com Zurbrugg, Meredith Monk comenta:

[...] penso que se poderia dizer que nosso mundo contemporâneo requer formas de percepção não lineares, simultâneas, como em um mosaico. Parece muito importante criar uma forma de arte que reflita isso - e também, em certo sentido, dar a oportunidade aos membros da audiência para sentir a plenitude de sua experiência e de todos os aspectos de si mesmo (Zurbrugg, 2004, p. 277). ${ }^{8}$

Além disso, existe em Juice outro aspecto relevante para a arte contemporânea, que diz respeito à interatividade. A intenção de tirar o público de sua passividade passa a fazer parte de muitas obras na atualidade. Em Juice, o público integra o espaço da performance, seus cenários, movimentando-se por estes e mixando-se com os performers. De fato, o público movendo-se pelo loft na última parte de Juice e tocando os diversos objetos, transforma-se ele próprio em performer. É através de sua ação, de sua trajetória e de sua movimentação que se completa a performance. Assim, Juice de Meredith Monk dissolve também as fronteiras entre performers e público, relativizando tais categorias.

Meredith Monk em entrevista a Nicholas Zurbrugg, comenta este período de grandes transformações artísticas como um movimento de aproximação e troca entre as diversas linguagens: "Havia um tanto de impulso naquele tempo para derrubar barreiras e encontrar novas maneiras de juntar as coisas, e uma troca maravilhosa e muito inspiradora entre artistas de diferentes mídias" (Zurbrugg, 2004, p. 274).

\footnotetext{
${ }^{8}$ I think you could say that our contemporary world requires a nonlinear, simultaneous, mosaiclike way of perceiving. It seems very important to create an art form which reflects that - and then also, in a sense, to give the opportunity to the members of the audience to sense the fullness of their experience and all aspects of themselves. (Tradução nossa)

${ }^{9}$ There was a bit impulse at that time to break down barriers and to find new ways of putting things together, and there was a wonderful, very inspirational exchange between artists from different media. (Tradução nossa)
} 
Deborah Jowitt cita a crítica M. B. Siegel para apontar Meredith Monk como uma das poucas artistas, que realmente conseguiram realizar o sonho da obra de arte total. Segundo Siegel, não seria possível determinar qual a mídia principal utilizada, quando se observa o trabalho final de Monk. E comenta a realização excepcional de Meredith Monk: "Considerando quantos artistas do teatro e da dança no século XX tem tentado uma tal síntese, e tão poucos que realmente conseguiram, a realização de Monk é duplamente impressionante" (Siegel apud Jowitt, 1997, p. 2) ${ }^{10}$.

Os processos de criação de Meredith Monk, embora deflagrados em geral pela exploração da voz, reúnem comumente diversas outras linguagens. Sua atuação artística ocorre frequentemente nas fronteiras, não apenas entre as diferentes linguagens e mídias, mas também no espaço das sutis fronteiras entre ficção e realidade, entre público e privado, explorando ainda a relativização de categorias antes estanques, tais como entre autor, intérprete/performer e público. Desta forma, sua produção questiona diversos limites transbordando frequentemente para fora destes. Ao atuar nos espaços "entre", leva também à dissolução das próprias fronteiras.

\section{Referências}

BERGER, Mark. A Metamorphic Theater. In: JOWITT, Deborah (Ed.) Meredith Monk. Baltimore: John Hopkins University Press, 1997. p. 44-48.

DUCKWORTH, William. Talking Music: conversations with John Cage, Philip Glass, Laurie Anderson, and five generations of American experimental composers. New York: Da Capo Press, 1999.

JOWITT, Deborah. (Ed.) Meredith Monk. Baltimore: John Hopkins University Press, 1997.

KLICH, Rosemary. SCHEER, Edward. Multimedia Performance. Basingstoke, England: Palgrave Macmillan, 2012.

MONK, Meredith. MARRANCA, Bonnie. Artist Talk. Meredith Monk em conversa com Bonnie Marranca: comemoração dos 150 da Brooklyn Academy of Music. (Informação Verbal). New York: BAM, 15 fev. 2012.

MONK, Meredith. MARRANCA, Bonnie. Conversations with Meredith Monk. New York: PAJ Publications, 2014.

ZURBRUGG, Nicholas. (Ed.) Art, Performance, Media: 31 Interviews. Minneapolis: University of Minnesota, 2004.

Recebido em: 20/05/2016 Aprovado em: 23/06/2017 ${ }^{10}$ Considering how many dance and theatre artists in the 20th century have tried for such a synthesis, and how few have truly accomplished it, Monk's achievement
is doubly impressive. (Tradução nossa) 